\title{
Digestive tract reconstruction of laparoscopic total gastrectomy for gastric cancer: a comparison of the intracorporeal overlap, intracorporeal hand-sewn anastomosis, and extracorporeal anastomosis
}

\author{
Zeshen Wang", Xirui Liu\#, Qingqing Cheng, Yuzhe Wei, Zhenglong Li, Guanyu Zhu, Yanfeng Li, \\ Kuan Wang \\ Department of Gastrointestinal Surgery, Harbin Medical University Cancer Hospital, Harbin, China \\ Contributions: (I) Conception and design: K Wang; (II) Administrative support: X Liu, Y Wei; (III) Provision of study materials or patients: Z Wang, \\ Y Li, G Zhu; (IV) Collection and assembly of data: Z Wang, Q Cheng, Z Li; (V) Data analysis and interpretation: Z Wang, X Liu,; (VI) Manuscript \\ writing: All authors; (VII) Final approval of manuscript: All authors. \\ \#These authors contributed equally to this work. \\ Correspondence to: Dr. Kuan Wang. Department of Gastrointestinal Surgery, Harbin Medical University Cancer Hospital, No.150, Haping Road, \\ Nangang District, Harbin 150086, China. Email: 0696@hrbmu.edu.cn.
}

Background: The application of esophagojejunostomy has certain difficulties in totally laparoscopic total gastrectomy (TLTG). This is due to the higher requirement for surgical techniques and the lack of any unified standards. This study aim to explore the practicability and safety of intracorporeal overlap and intracorporeal hand-sewn anastomosis compared with extracorporeal anastomosis.

Methods: The clinical pathological data of 56 patients who underwent TLTG from March 2016 to December 2020 in the Harbin Medical University Cancer Hospital were retrospectively analyzed. According to the method of anastomosis, the patients were divided into the overlap $(n=36)$ and the hand-sewn anastomosis $(n=20)$. Patients who receive laparoscopic-assisted total gastrectomy (LATG; $n=74)$ formed the control group. The basic clinical data, and intraoperative and postoperative results of the patients were assessed.

Results: Compared with the control group, the overlap anastomosis and hand-sewn anastomosis groups showed no significant differences in clinicopathological data and short-term postoperative recovery. There were no significant differences between the overlap and the control group in operation time nor anastomosis time. However, the anastomosis time of the hand-sewn anastomosis group was significantly prolonged compared to the control group $(53.20 \pm 14.14$ vs. $43.01 \pm 12.53$ minutes, $\mathrm{P}=0.002)$. Compared with the control group, the operation cost was significantly higher in the overlap group (CNY 81,300 $\pm 6,100$ vs. CNY

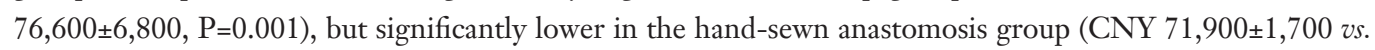
CNY 76,600 $\pm 6,800, \mathrm{P}=0.003)$. Early postoperative complications occurred in 5 cases (13.9\%) in the overlap group, 3 cases $(15.0 \%)$ in the hand-sewn anastomosis group, and 11 cases $(14.9 \%)$ in the control group. There were 3 cases $(8.3 \%)$ of postoperative anastomotic-related complications in the overlap group. No anastomotic-related complications were observed in the hand-sewn anastomosis group.

Conclusions: The overlap anastomosis and hand-sewn anastomosis are practical and safe. Furthermore, the overlap anastomosis may be more suitable for patients with lower cardia and fundic lesions. The hand-sewn method has a wider range of indications pending advanced surgical skills, and is an effective supplementary technique for instrument anastomosis.

Keywords: Gastric cancer; overlap; hand-sewn; circular stapler; linear stapler; totally laparoscopic total gastrectomy (TLTG) 
Submitted Mar 26, 2021. Accepted for publication May 27, 2021.

doi: 10.21037/jgo-21-231

View this article at: http://dx.doi.org/10.21037/jgo-21-231

\section{Introduction}

Laparoscopic-assisted Billroth I gastrectomy for the treatment of early gastric cancer was first reported in 1994 by Kitano et al. (1). So far, several prospective randomized controlled trials (RCT) on laparoscopic distal gastrectomy (LDG) have been successfully carried out, and proved to be technically and oncologically feasible (2-5). However, laparoscopic total gastrectomy (LTG) for the management of gastric cancer is still encumbered with challenges as there are no uniform operating standards for laparoscopic digestive reconstruction and it requires advanced surgical techniques (6-9).

In totally laparoscopic total gastrectomy (TLTG), instrument anastomosis is the main method for digestive tract reconstruction. However, this can be complicated by issues such as the inconvenient placement of the circular stapler anvil and limitations of the linear stapler by the location of the tumor $(8,10,11)$. Hand-sewn anastomosis has fewer clinical applications and higher requirements for good suture techniques. However, advantages associated with this method, including a tension-free suture process, good blood supply, and a convenient cutting edge. Under the premise of skilled technology, it is also a surgical method in line with the concept of laparoscopy (12-14). This study retrospectively analyzed the intraoperative and postoperative results and related complications of intracorporeal overlap and intracorporeal hand-sewn anastomosis, and compared with LATG, which is widely used in clinical practice, to explore the advantages of two kinds of intracorporeal anastomosis and summarize the indications. We present the following article in accordance with the STROBE reporting checklist (available at http://dx.doi.org/10.21037/jgo-21-231).

\section{Methods}

\section{Patients}

The clinical data of all upper gastric cancer patients who underwent LTG in the Second Ward of the Gastrointestinal Surgery Department of the Harbin Medical University Cancer Hospital from March 2016 to December 2020 were retrospectively collated and analyzed. Cases were selected according to the following inclusion criteria: (I) confirmation of gastric cancer by preoperative pathological diagnosis; (II) clinical stage I-III; and (III) operation performed by the same group of doctors. Patients were excluded from this study if they presented with the following: (I) a history of stomach surgery; (II) other malignant tumors; (III) comorbid serious systemic diseases such as hypertension and diabetes; and (IV) a history of preoperative radiotherapy and chemotherapy.

After applying the inclusion and exclusion criteria, a total of 130 patients were finally enrolled in this study. Considering the basic clinical data and economic situation of patients, the cohort was divided into the overlap group $(\mathrm{n}=36)$, the hand-sewn anastomosis group $(\mathrm{n}=20)$, and the LATG (control group; $n=74$ ). All patients signed informed consent. This study was performed in accordance with the ethical standards of the Human Subjects Responsibility Committee (institutions and countries), and the Helsinki Declaration (as revised in 2013). This research was approved by the Ethics Committee of the Harbin Medical University Cancer Hospital (Ethics number: 2018-78-R).

\section{Surgical procedure}

Following induction of general anesthesia, patients were placed in the supine position. A small incision was made $1 \mathrm{~cm}$ above the umbilicus where a $10 \mathrm{~mm}$ trocar was positioned. Pneumoperitoneum was established and maintained at $14 \mathrm{mmHg}$ pressure. The cavity was explored and after no visible peritoneal metastasis and ascites were confirmed, two $12 \mathrm{~mm}$ trocars were placed in the left and right lower abdomen, and two $5 \mathrm{~mm}$ trocars were placed in the left and right upper abdomen, as shown in Figure 1. Standard D2 lymph node dissection and tumor radical resection was then performed.

\section{Reconstruction of the digestive tract}

Laparoscope-assisted circular stapler for extracorporeal anastomosis

For complete lymph node dissection under laparoscopy, a small $3-5 \mathrm{~cm}$ incision was made in the upper abdomen, the specimen was removed, and an anvil was placed at the distal 
end of the esophagus with purse-string forceps. Roux-en-Y anastomosis was performed.

\section{The overlap method}

The abdominal esophagus was fully freed, the jejunum was cut with a $60 \mathrm{~mm}$ stapler that was $15-20 \mathrm{~cm}$ away from the ligament of Treitz, the center of the distal end of the esophageal stump was punched, and a small incision was made on the dorsal intestinal wall of the mesentery $7 \mathrm{~cm}$ away from the anastomosis line in the distal jejunum (Figure 2A). Side-to-side anastomosis of the left anterior wall of the esophagus and the posterior wall of the jejunum was performed (Figure 2B). The common opening was closed by hand-sewn anastomosis (Figure 2C), and the jejunojejunostomy side-to-side anastomosis was performed

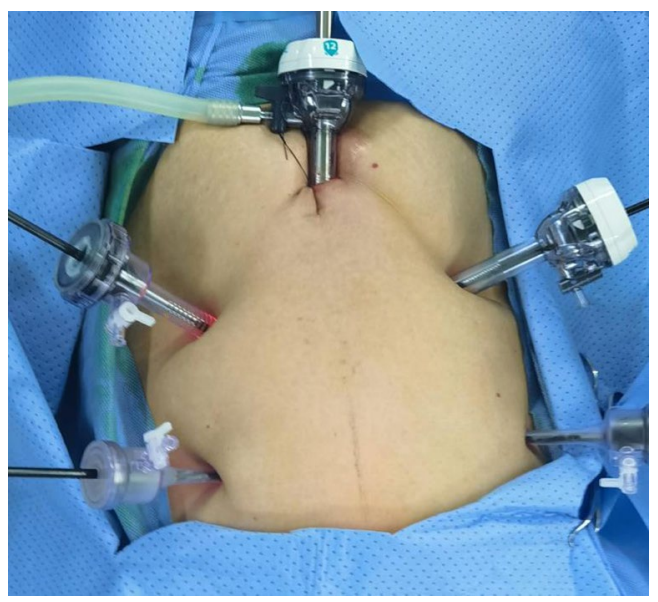

Figure 1 Location and distribution of trocars. at a distance of $50 \mathrm{~cm}$ from the esophageal jejunostomy to close the common opening.

\section{Hand-sewn anastomosis}

The jejunum was cut with a $60 \mathrm{~mm}$ stapler that was 20-25 cm away from the ligament of Treitz. Barbed thread was used to suture the posterior wall of the esophageal stump and the posterior jejunum from right to left. The barbed thread was indwelled and a matching small incision was made in the esophagus and jejunum (Figure 3A). The seromuscular layer of the posterior wall of the anastomotic stoma was sutured continuously with barbed thread, and then the whole layer of the posterior wall was sutured intermittently. The suture direction was from right to left using varus suture (Figure 3B). The whole anterior wall of the anastomosis was sutured intermittently, and the seromuscular layer of the anterior wall was sutured continuously with barbed thread, from left to right, using valgus suture (Figure 3C).

\section{Observation index}

General clinical data (gender, age, BMI, ASA score, tumor location, preoperative comorbidities, preoperative anemia, preoperative hypoproteinemia, history of abdominal surgery, pTNM stage). Intraoperative and postoperative short-term results (blood loss, operation time, anastomosis time, time to first postoperative liquid diet, time to first postoperative flatulence, postoperative hospital stay), and postoperative complications (anastomotic leakage, anastomotic bleeding, anastomotic stenosis, intra-abdominal bleeding, duodenal stump leakage, abdominal infection, intestinal obstruction,
A

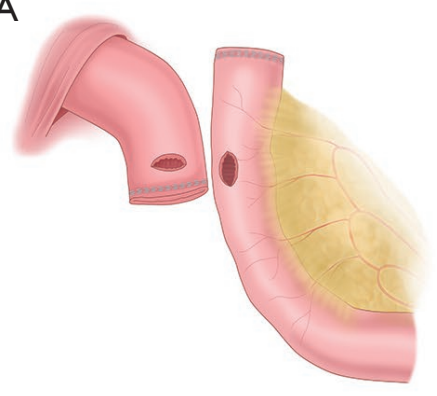

B

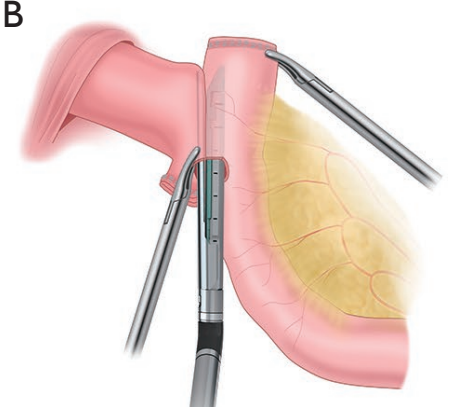

C

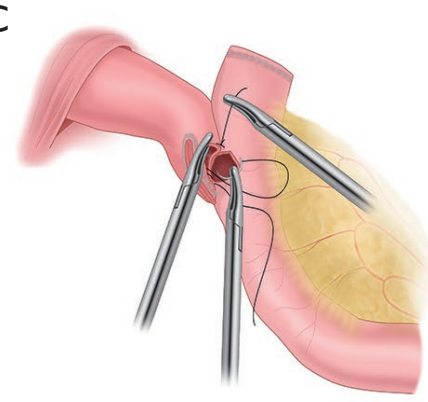

Figure 2 Overlap anastomosis. (A) A small incision was made in the center of the distal esophageal stump and the dorsal wall of mesentery. (B) The anterior wall of esophagus was anastomosed with the posterior wall of jejunum. (C) The common opening was closed by hand-sewn anastomosis. 
A

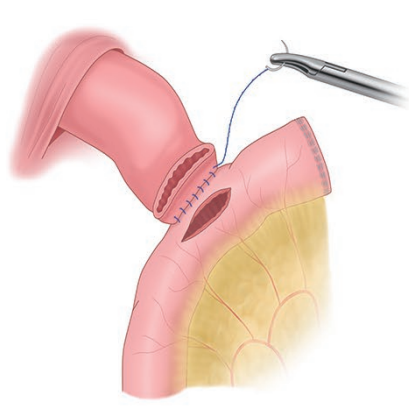

B

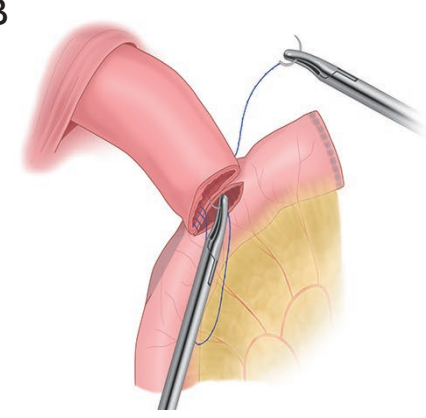

C

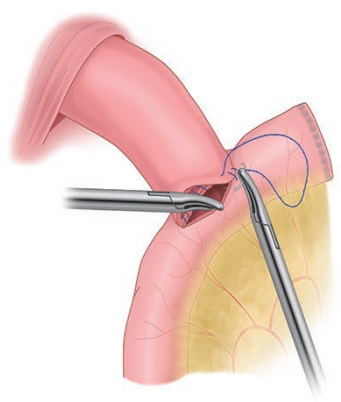

Figure 3 Hand-sewn anastomosis. (A) Continuous suture along the posterior wall of the esophageal stump and the posterior wall of the jejunum. Matching incisions were made. (B) Continuous suture of the posterior wall of the anastomosis. (C) Continuous suture of the anterior wall of the anastomosis.

pancreatic leakage, pulmonary infection, incision infection, esophageal hiatal hernia, etc.).

\section{Postoperative management and follow-up}

The gastric tube was pulled out on the first day postsurgery. Patients were allowed to drink a small amount of water intermittently and encouraged to move out of bed. Computed tomography (CT) and digestive tract radiography were performed on the 5 th day post-operation to assess the presence of any anastomotic leakage. Patients were discharged 7-8 days post-operation. After discharge, patients were followed up for complications related to anastomoses. At 6 months post-surgery, patients were examined for anastomotic stenosis by electronic gastroscopy.

\section{Statistical methods}

Statistical analyses were conducted using SPSS 22.0 statistical software. The measurement data conforming to normal distribution are expressed as mean \pm standard deviation $(\bar{x} \pm \mathrm{s})$, and the independent sample $t$ test was used for comparison between groups. Categorical variables were compared using the chi-squared or Fisher test. Univariate and multivariate binary logistic regression models were used to analyze the risk factors of complications. A $\mathrm{P}$ value $<0.05$ was considered statistically significant.

\section{Results}

\section{Basic clinicopathological features}

The clinicopathological characteristics of the three groups of patients are shown in Table 1. Compared with the basic clinical data of the control group, there were no statistically significant differences in either the overlap group nor the hand-sewn group. The distance from the upper edge of the tumor to the resection edge of the esophagus was analyzed in the three groups. This distance was shorter in the overlap group compared to the control group $(2.54 \pm 0.73$ vs. $4.26 \pm 0.86 \mathrm{~cm}, \mathrm{P}<0.001)$ and the hand-sewn anastomosis group $(2.54 \pm 0.73$ vs. $3.93 \pm 0.83 \mathrm{~cm}, \mathrm{P}<0.001)$. There was no significant difference between the hand-sewn anastomosis group and the control group (Figure 4). In this study, the median follow-up time was 24 months for patients in the overlap group was, 12 months for the hand-sewn anastomosis group, and 33 months for the control group.

\section{Intraoperative and postoperative results}

The intraoperative and early postoperative results are shown in Table 2. In the overlap and the control group, the operation time (measured from when the first Trocar is inserted to closure of the abdominal cavity) $(194.94 \pm 25.20$ vs. $190.49 \pm 33.77$ minutes, $\mathrm{P}=0.484)$ and the anastomosis time (from the beginning of the hole or anvil placement to the end of the suture) $(42.17 \pm 10.20 v \mathrm{~s}$. $43.01 \pm 12.53$ minutes, $\mathrm{P}=0.725)$ were similar. The average blood loss in the overlap group was lower than that of the control group, but the difference was not significant $(68.61 \pm 38.65$ vs. $79.86 \pm 44.37 \mathrm{~mL}, \mathrm{P}=0.196)$. There is no difference in short-term results between the overlap and the control group, including time to first flatulence, time to first liquid diet, and postoperative hospital stay. However, the cost of surgery in the overlap group was significantly higher than that in the control group (CNY 81,300 $\pm 6,100$ vs. CNY $76,600 \pm 6,800, \mathrm{P}=0.001)$. 
Table 1 General clinical data of the patients

\begin{tabular}{|c|c|c|c|c|c|}
\hline Variable & Overlap & Hand-sewn & Control & \multicolumn{2}{|c|}{$\mathrm{P}$} \\
\hline Gender & & & & 0.59 & 0.698 \\
\hline Male & $25(69.4)$ & $14(70.0)$ & $55(74.3)$ & & \\
\hline Female & $11(30.6)$ & $6(30.0)$ & $19(25.7)$ & & \\
\hline $\mathrm{BMI}\left(\mathrm{kg} / \mathrm{m}^{2}\right)$ & $23.6 \pm 3.8$ & $23.9 \pm 3.0$ & $22.7 \pm 3.4$ & 0.233 & 0.157 \\
\hline ASA score & & & & 0.504 & 0.836 \\
\hline I & $22(61.1)$ & $14(70.0)$ & $50(67.6)$ & & \\
\hline ॥ & $14(38.9)$ & $6(30.0)$ & $24(32.4)$ & & \\
\hline $\begin{array}{l}\text { Gastroesophageal } \\
\text { junction }\end{array}$ & $17(47.2)$ & $11(55.0)$ & 27 (36.5) & & \\
\hline Body of stomach & $19(52.8)$ & $9(45.0)$ & $47(63.5)$ & & \\
\hline $\begin{array}{l}\text { Preoperative } \\
\text { complications }\end{array}$ & & & & 0.911 & 0.874 \\
\hline 0 & $21(58.3)$ & $11(55.0)$ & $43(58.1)$ & & \\
\hline 1 & $12(33.3)$ & $6(30.0)$ & $23(31.1)$ & & \\
\hline 2 & $3(8.3)$ & $3(15.0)$ & $8(10.8)$ & & \\
\hline TNM staging & & & & 0.11 & 0.152 \\
\hline I & $12(33.3)$ & $7(35.0)$ & $13(17.8)$ & & \\
\hline II & $14(38.9)$ & $8(40.0)$ & $27(37.0)$ & & \\
\hline III & $10(27.8)$ & $5(25.0)$ & $33(45.2)$ & & \\
\hline IV & 0 & 0 & 0 & & \\
\hline $\begin{array}{l}\text { Distance from upper edge } \\
\text { of tumor to resection edge } \\
\text { of esophagus }\end{array}$ & $2.54 \pm 0.73$ & $3.93 \pm 0.83$ & $4.26 \pm 0.86$ & $<0.001$ & 0.116 \\
\hline Follow-up time (months) & 24 & 12 & 33 & & \\
\hline
\end{tabular}

Data are expressed as mean \pm standard deviation or $n$ (\%). ASA, American Society of Anesthesiologists score; TNM, tumor, node, metastasis stage. 
Compared with the control group, the operation time of the hand-sewn anastomosis group was longer (204.70 \pm 20.72 vs. $190.49 \pm 33.77$ minutes, $\mathrm{P}=0.085)$, and the anastomosis time was significantly longer $(53.20 \pm 14.14 \mathrm{vs}$. $43.01 \pm 12.53$ minutes, $\mathrm{P}=0.002)$. The bleeding volume was similar between the two groups $(75.00 \pm 37.59$ vs. $79.86 \pm$ $44.37 \mathrm{~mL}, \mathrm{P}=0.353)$. There were no significant differences in the time to first flatulence, time to first liquid diet, and the postoperative hospital stay between the two groups. The operation cost of the hand-sewn anastomosis group was significantly reduced compared to the control group (CNY $71,900 \pm 1,700$ vs. CNY 76,600 $\pm 6,800, \mathrm{P}=0.003)$.

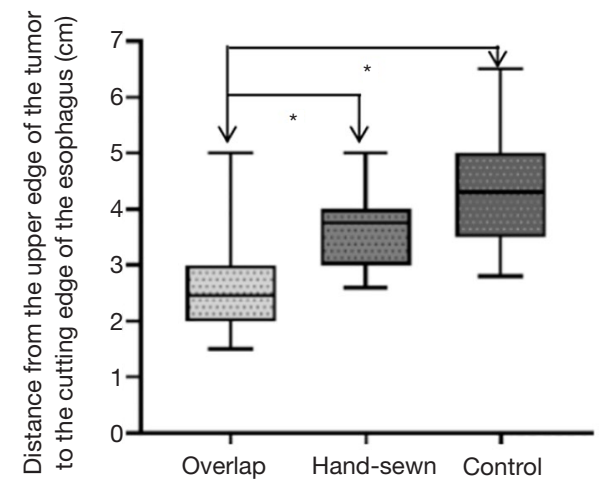

Figure 4 The distance from the upper edge of the tumor to the cutting edge of the esophagus in the overlap group was shorter than that in the hand-sewn anastomosis group and the control group. *, $\mathrm{P}<0.05$.

\section{Postoperative complications}

There were no deaths in hospital or within 30 days postsurgery. The postoperative complications are shown in Table 3. There were 5 cases $(13.8 \%)$ of postoperative complications in the overlap group, 3 cases $(15 \%)$ in the hand-sewn anastomosis group, and 11 cases (14.8\%) in the control group. In the overlap group, early anastomoticrelated complications included 1 case of anastomotic leakage and 2 cases of anastomotic bleeding. There were no anastomotic-related complications in the hand-sewn anastomosis group. In the control group, there were 2 cases of anastomotic leakage and 1 case of anastomotic bleeding. Complications that occurred one month postoperation were included in the long-term postoperative complications. These were mainly anastomotic-related complications. There was no anastomotic stenosis in the overlap group and the hand-sewn anastomosis group during the follow-up period. In the control group, there were 2 cases of anastomotic stenosis. No hiatal hernia was detected in any of the three groups.

\section{Risk factors of complications after complete laparoscopic intracorporeal anastomosis}

Univariate analysis demonstrated that the number of preoperative complications, operation time, anastomosis time, and intraoperative blood loss were all related to postoperative complications (Table 4). Multivariate analysis of these factors showed that preoperative complications

Table 2 Operative and postoperative results

\begin{tabular}{|c|c|c|c|c|c|}
\hline \multirow{2}{*}{ Clinical outcome data } & \multirow{2}{*}{ Overlap } & \multirow{2}{*}{ Hand-sewn } & \multirow{2}{*}{ Control } & \multicolumn{2}{|c|}{$\mathrm{P}$} \\
\hline & & & & Overlap vs. Control & Hand-sewn vs. Control \\
\hline Operation time (min) & $194.94 \pm 25.20$ & $204.70 \pm 20.72$ & $190.49 \pm 33.77$ & 0.484 & 0.085 \\
\hline Anastomosis time (min) & $42.17 \pm 10.20$ & $53.20 \pm 14.14$ & $43.01 \pm 12.53$ & 0.725 & 0.002 \\
\hline Blood loss (mL) & $68.61 \pm 38.65$ & $75.00 \pm 37.59$ & $79.86 \pm 44.37$ & 0.196 & 0.353 \\
\hline $\begin{array}{l}\text { Time to first postoperative } \\
\text { flatulence (days) }\end{array}$ & $3.56 \pm 0.81$ & $3.80 \pm 0.77$ & $3.53 \pm 0.75$ & 0.754 & 0.164 \\
\hline Postoperative hospital stay (days) & $7.67 \pm 1.43$ & $7.9 \pm 0.79$ & $8.12 \pm 1.99$ & 0.223 & 0.626 \\
\hline Secondary operation & 0 & 0 & 1 & & \\
\hline
\end{tabular}

Data are expressed as mean \pm standard deviation or $\mathrm{n}(\%)$. 
Table 3 Postoperative complications

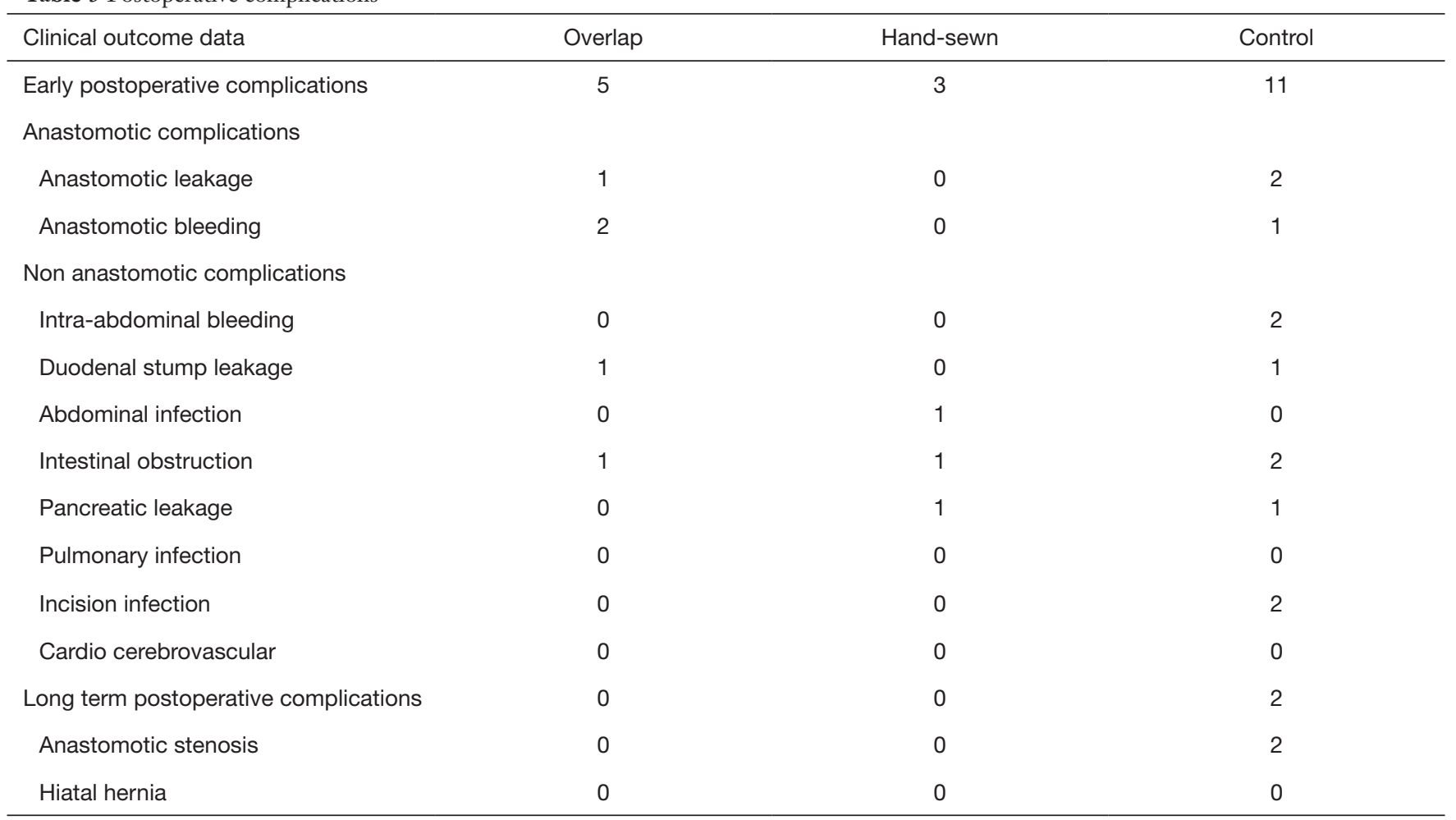

[odds ratio (OR) 4.90, 95\% confidence interval (CI): 1.23 to 16.17], operation time (OR 1.08, 95\% CI: 1.01 to 1.16 ), and intraoperative blood loss (OR 1.03, 95\% CI: 1.00 to 1.05 ) were independent predictors of complications after TLTG.

\section{Discussion}

LTG has been reported since 1999 (15). LATG is more common in clinical practice due to its advantage of being closer to the open state and its non-inferiority to open total gastrectomy (OTG) (16). However, TLTG has not been widely used due to its high technical requirements and the lack of unified standards for digestive tract reconstruction. Laparoscopic esophagojejunostomy is the key to the completion of TLTG. In addition to the longterm oncology results of patients, it has been reported that inappropriate anastomosis can cause postoperative complications $(17,18)$. Therefore, understand the indications and contra-indications for each TLTG anastomosis method is crucial to the successful treatment of the patient.

In principle, the criteria for successful reconstruction of esophageal jejunal anastomosis include sufficient blood supply and tension-free anastomosis. Use of the circular stapler and hand-sewn anastomosis can achieve the smallest separation of the esophageal stump while maintaining the blood supply of the anastomosis. However, If the location of the tumor is high, it will be difficult to insert the anvil in the extracorporeal anastomosis. In addition, the operation related to anastomosis can also be affected by factors such as body mass index (BMI) and thoracic type. The linear stapler can produce anastomotic stoma larger than $30 \mathrm{~mm}$ in diameter, which may have advantages in reducing anastomotic stenosis. In fact, it has been reported that the incidence of anastomotic leakage and stenosis associated with the linear stapler is relatively low compared to that of the circular stapler $(7,19)$. However, it has been shown that anastomotic tension can significantly increase anastomotic complications (20) and the use of linear stapler needs to reserve a long esophageal stump. Therefore, for patients with high lesion locations, considering the high tension, blood supply and the safety of the proximal margin, side-to-side anastomosis is not optimal. Compared with instrument anastomosis, hand-sewn anastomosis is a simple and economical surgical technique, which can monitor the whole process of suture and as a result, the anastomosis more reliable. However, this method is not yet in mainstream clinical use as it has higher requirements for 
Table 4 Risk factors for postoperative complication after intracorporeal anastomosis

\begin{tabular}{lccc}
\hline \multirow{2}{*}{ Variable } & \multicolumn{2}{c}{ Univariate } & Multivariate \\
\cline { 2 - 3 } Age & OR $(95 \% \mathrm{Cl})$ & $\mathrm{P}$ & $\mathrm{OR}(95 \% \mathrm{Cl})$ \\
Sex & $1.04(0.96-1.14)$ & 0.323 & 0.723 \\
BMI & $0.73(0.13-4.07)$ & 0.101 & $0.90(1.19-20.09)$ \\
Preoperative complications & $1.25(0.86-1.63)$ & 0.016 & 0.027 \\
ASA score & $3.83(1.28-11.47)$ & 0.909 & 0.360 \\
Preoperative anemia & $1.09(0.23-5.15)$ & 0.264 & $1.08(1.01-1.16)$ \\
Preoperative hypoproteinemia & $2.33(0.38-14.2)$ & 0.011 & $0.97(0.88-1.06)$ \\
Operation time & $2.87(0.45-18.21)$ & 0.042 & 0.029 \\
Anastomosis time & $1.07(1.02-1.12)$ & 0.017 & 0.970 \\
Blood loss & $1.06(1.00-1.13)$ & $1.00-1.05)$ & 0.041 \\
\hline
\end{tabular}

OR, odds ratio; Cl, confidence interval; BMI, body mass index; ASA, American Society of Anesthesiologists score.

appropriate equipment and more advanced surgical skills (6). Therefore, considering the limitations of the extracorporeal anastomosis, the clinical application and value of the intracorporeal linear stapler and intracorporeal hand-sewn anastomosis were explored.

Statistical data showed that there were no significant differences between the overlap group and the control group in the basic data of clinical pathology, blood loss, and short-term postoperative results. The operation time and anastomosis time were relatively balanced. Reasons that can help save time may include as follows: (I) our team improved the method of overlap anastomosis, simplified the operation steps, and did not rotate the esophageal stump. Esophagojejunostomy was performed on the anterior wall of the esophageal stump. After closure, visibility of the common opening was improved. (II) The operator has many years of experience in totally laparoscopy distal gastrectomy (TLDG) operations. This, combined with the use of barbed suture effectively shortened the closing time of the common opening. Due to the limitation of operation space and the possibility of stenosis, barbed suture has been widely used in a variety of surgical operations, and it has been shown to significantly shorten the suture time under laparoscopic (21-23). In addition, the team's overlap experience includes: (III) the author recommend that the jejunum be disconnected first. This allows sufficient time to observe the blood supply of the jejunum after it is disconnected. But we also found that it is relatively difficult to prune the mesentery under laparoscopy. (IV) We found it was convenient and safe to cut the cutting edge in the specimen bag under laparoscopic guidance and remove the spoon forceps. (V) We can see from Figure 4 that overlap method is more likely to be limited by the location of the tumor, so it may not be suitable for the upper middle position of the cardia and in the case of esophageal wall edema, the risk of bleeding after closure is relatively increased. (VI) Notably, there have been increasing reports of hiatal hernias after LTG linear stapler use (24), which may be due to the separation of the left diaphragm during the operation, followed by distortion of Roux intestinal loop, and sliding of anastomotic stoma, resulting in gastrointestinal obstruction. Separation or injury to the diaphragm should be repaired and the Roux intestinal loop should be fix at the hiatal site to minimize the occurrence of hiatal hernias.

In comparison, we found that intracorporeal hand-sewn anastomosis and extracorporeal circular anastomosis were similar during the operation, and both were end-to-side anastomosis, although the anastomosis time was prolonged due to the initial operation. Indeed, longer operation times may have adverse impacts on the prognosis of patients (25). However, patients in the hand-sewn anastomosis group have achieved satisfactory results in terms of postoperative recovery and complications. In our experience, an optimal anastomosis area is crucial to the length of anastomosis time. Good control of the operation field requires effective fixation measures for the left lateral lobe of the liver, esophagus, and jejunum stump. The continuous suture between the posterior wall of the esophageal stump and the 
posterior wall of the jejunum used by our surgical team can achieve a good fixation effect and prevent the esophageal stump from retracting. At the same time, the continuous suture of the plasma muscular layer of the anterior and posterior walls of the anastomotic stoma through the barbed thread combined with the full-thickness intermittent suture is more reliable. In addition, before suture, it is recommended to use an attractor to fully attract digestive fluid, and then suture it to prevent contamination caused by leakage of digestive fluid. Lastly, the anastomotic plane of hand-sewn anastomosis is similar to that of extracorporeal anastomosis, which is higher than overlap method. Therefore, on condition of skilled technique, hand-sewn anastomosis may have a wider adaptability for tumor location.

Anastomotic stenosis is a significant complication affecting a patient's quality of life after total gastrectomy. It has been reported that there is a correlation between the incidence of anastomotic stenosis and circular staplers (26), however, this latter study was not a systematic investigation and future large-scale clinical studies should be conducted to confirm this association. In this study, no anastomotic stenosis occurred in the intracorporeal anastomotic group, especially hand-sewn anastomotic, no anastomotic related complications. The author believes that with the increase of hand-sewn anastomotic operation, the technical concept is more mature, and its application prospect should be more extensive.

Therefore, if the operator has passed the learning curve, the intracorporeal anastomosis will be more suitable for clinical practice, and the advantage is more obvious. Regarding the choice of anastomosis method for LTG treatment of gastric cancer, the author believes that it should be considered comprehensively from both the operator and the patient. In terms of the operator, the position of the operator in the learning curve and the operator's habits are included. The patients' health, clinical stage, tumor location, economic situation and other factors are included. The surgeon should combine two aspects and choose flexibly.

This retrospective study was conducted in a single institution. The patients were non-random, and the sample size was small. Furthermore, there may be bias in the selection. For example, for patients with early clinical stage gastric cancer and patients with obesity, the overlap and hand-sewn anastomosis methods were preferred. This study demonstrated that the three anastomosis methods have their own advantages, and future prospective randomized controlled trials with larger sample sizes are warranted to verify these results.

\section{Conclusions}

Both overlap and hand-sewn anastomosis are safe and feasible, and the use of the overlap method is more minimally invasive. The overlap anastomosis method is recommended for patients with lower cardia and gastric fundus lesions. Extracorporeal circular stapler anastomosis and intracorporeal hand-sewn anastomosis have better adaptability to tumor location. If the surgeon has advanced suture skills, the hand-sewn anastomosis method may be more suitable for certain patients such as those with esophageal wall edema and obesity, and it is the key supplement of instrument anastomosis. The operating surgeon should consider all indications prior to deciding upon the optimal method.

\section{Acknowledgments}

Funding: This work was funded by the Harbin Medical University Cancer Hospital (Nn10PY2017-03) and the Haiyan Fund, Harbin Medical University Cancer Hospital (JJED2016-02).

\section{Footnote}

Reporting Checklist: The authors have completed the STROBE reporting checklist. Available at http://dx.doi. org/10.21037/jgo-21-231

Data Sharing Statement: Available at http://dx.doi. org/10.21037/jgo-21-231

Conflicts of Interest: All authors have completed the ICMJE uniform disclosure form (available at http://dx.doi. org/10.21037/jgo-21-231). The authors have no conflicts of interest to declare.

Ethical Statement: The authors are accountable for all aspects of the work in ensuring that questions related to the accuracy or integrity of any part of the work are appropriately investigated and resolved. All patients signed informed consent. This study was performed in accordance with the ethical standards of the Human Subjects Responsibility Committee (institutions and countries), and the Helsinki Declaration (as revised in 2013). This 
research was approved by the Ethics Committee of the Harbin Medical University Cancer Hospital (Ethics number: 2018-78-R).

Open Access Statement: This is an Open Access article distributed in accordance with the Creative Commons Attribution-NonCommercial-NoDerivs 4.0 International License (CC BY-NC-ND 4.0), which permits the noncommercial replication and distribution of the article with the strict proviso that no changes or edits are made and the original work is properly cited (including links to both the formal publication through the relevant DOI and the license). See: https://creativecommons.org/licenses/by-nc-nd/4.0/.

\section{References}

1. Kitano S, Iso Y, Moriyama M, et al. Laparoscopyassisted Billroth I gastrectomy. Surg Laparosc Endosc 1994;4:146-8.

2. Kim HH, Han SU, Kim MC, et al. Effect of Laparoscopic Distal Gastrectomy vs Open Distal Gastrectomy on Long-term Survival Among Patients With Stage I Gastric Cancer: The KLASS-01 Randomized Clinical Trial. JAMA Oncol 2019;5:506-13.

3. Kim W, Kim HH, Han SU, et al. Decreased Morbidity of Laparoscopic Distal Gastrectomy Compared With Open Distal Gastrectomy for Stage I Gastric Cancer: Short-term Outcomes From a Multicenter Randomized Controlled Trial (KLASS-01). Ann Surg 2016;263:28-35.

4. Lee HJ, Hyung WJ, Yang HK, et al. Short-term Outcomes of a Multicenter Randomized Controlled Trial Comparing Laparoscopic Distal Gastrectomy With D2 Lymphadenectomy to Open Distal Gastrectomy for Locally Advanced Gastric Cancer (KLASS-02-RCT). Ann Surg 2019;270:983-91.

5. Shi Y, Xu X, Zhao Y, et al. Short-term surgical outcomes of a randomized controlled trial comparing laparoscopic versus open gastrectomy with D2 lymph node dissection for advanced gastric cancer. Surg Endosc 2018;32:2427-33.

6. Kawaguchi Y, Shiraishi K, Akaike H, et al. Current status of laparoscopic total gastrectomy. Ann Gastroenterol Surg 2019;3:14-23.

7. Kim EY, Choi HJ, Cho JB, et al. Totally Laparoscopic Total Gastrectomy Versus Laparoscopically Assisted Total Gastrectomy for Gastric Cancer. Anticancer Res 2016;36:1999-2003.

8. Lee S, Lee H, Song JH, et al. Intracorporeal esophagojejunostomy using a linear stapler in laparoscopic total gastrectomy: comparison with circular stapling technique. BMC Surg 2020;20:100.

9. Son SY, Cui LH, Shin HJ, et al. Modified overlap method using knotless barbed sutures (MOBS) for intracorporeal esophagojejunostomy after totally laparoscopic gastrectomy. Surg Endosc 2017;31:2697-704.

10. Huang C, Zhao J, Liu Z, et al. Esophageal Suspension Method for Hand-Sewn Esophagojejunostomy After Totally Laparoscopic Total Gastrectomy: A Simple, Safe, and Feasible Suturing Technique. Front Oncol 2020;10:575.

11. Miura S, Kanaya S, Hosogi H, et al. Esophagojejunostomy With Linear Staplers in Laparoscopic Total Gastrectomy: Experience With 168 Cases in 5 Consecutive Years. Surg Laparosc Endosc Percutan Tech 2017;27:e101-7.

12. Chen K, Wu D, Pan Y, et al. Totally laparoscopic gastrectomy using intracorporeally stapler or hand-sewn anastomosis for gastric cancer: a single-center experience of 478 consecutive cases and outcomes. World J Surg Oncol 2016;14:115.

13. Norero E, Munoz R, Ceroni M, et al. Two-Layer HandSewn Esophagojejunostomy in Totally Laparoscopic Total Gastrectomy for Gastric Cancer. J Gastric Cancer 2017;17:267-76.

14. Sun Z, Zheng X, Chen G, et al. Technical details of and prognosis for the "China stitch", a novel technique for totally laparoscopic hand-sewn esophagojejunostomy. Biosci Trends 2020;14:56-63.

15. Azagra JS, Goergen M, De Simone P, et al. Minimally invasive surgery for gastric cancer. Surg Endosc 1999;13:351-7.

16. Etoh T, Honda M, Kumamaru H, et al. Morbidity and mortality from a propensity score-matched, prospective cohort study of laparoscopic versus open total gastrectomy for gastric cancer: data from a nationwide web-based database. Surg Endosc 2018;32:2766-73.

17. K ATMA, Murakami Y, Yoshimoto $M$, et al. IntraAbdominal Complications after Curative Gastrectomies Worsen Prognoses of Patients with Stage II-III Gastric Cancer. Yonago Acta Med 2016;59:210-6.

18. Kawase H, Ebihara Y, Shichinohe T, et al. Longterm outcome after laparoscopic gastrectomy: a multicenter retrospective study. Langenbecks Arch Surg 2017;402:41-7.

19. Gong CS, Kim BS, Kim HS. Comparison of totally laparoscopic total gastrectomy using an endoscopic linear stapler with laparoscopic-assisted total gastrectomy using a circular stapler in patients with 
gastric cancer: A single-center experience. World J Gastroenterol 2017;23:8553-61.

20. Okata Y, Maeda K, Bitoh Y, et al. Evaluation of the intraoperative risk factors for esophageal anastomotic complications after primary repair of esophageal atresia with tracheoesophageal fistula. Pediatr Surg Int 2016;32:869-73.

21. Arena A, Degli Esposti E, Cristani G, et al. Comparison of fertility outcomes after laparoscopic myomectomy for barbed versus nonbarbed sutures. Fertil Steril 2021;115:248-55.

22. Morelli L, Furbetta N, Gianardi D, et al. Use of barbed suture without fashioning the "classical" Wirsungjejunostomy in a modified end-to-side robotic pancreatojejunostomy. Surg Endosc 2021;35:955-61.

23. Peleg D, Ahmad RS, Warsof SL, et al. A randomized clinical trial of knotless barbed suture vs conventional

Cite this article as: Wang Z, Liu X, Cheng Q, Wei Y, Li Z, Zhu G, Li Y, Wang K. Digestive tract reconstruction of laparoscopic total gastrectomy for gastric cancer: a comparison of the intracorporeal overlap, intracorporeal hand-sewn anastomosis, and extracorporeal anastomosis. J Gastrointest Oncol 2021;12(3):1031-1041. doi: 10.21037/jgo-21-231 suture for closure of the uterine incision at cesarean delivery. Am J Obstet Gynecol 2018;218:343.e1-343.e7.

24. Ito E, Ohdaira H, Nakashima K, et al. Crus incision without repair is a risk factor for esophageal hiatal hernia after laparoscopic total gastrectomy: a retrospective cohort study. Surg Endosc 2017;31:237-44.

25. Carter J, Elliott S, Kaplan J, et al. Predictors of hospital stay following laparoscopic gastric bypass: analysis of 9,593 patients from the National Surgical Quality Improvement Program. Surg Obes Relat Dis 2015;11:288-94.

26. Umemura A, Koeda K, Sasaki A, et al. Totally laparoscopic total gastrectomy for gastric cancer: literature review and comparison of the procedure of esophagojejunostomy. Asian J Surg 2015;38:102-12.

(English Language Editor: J. Teoh) 